\title{
PSO-Backstepping controller of a grid connected DFIG based wind turbine
}

\author{
Salmi Hassan', Badri Abdelmajid ${ }^{2}$, Zegrari Mourad $^{3}$, Sahel Aicha ${ }^{4}$, Baghdad Abdennaceur $^{5}$ \\ ${ }_{1,2,4,5}$ EEA \& TI Laboratory Faculty of Sciences and Techniques, Hassan II Casablanca University, Morocco \\ ${ }^{3}$ Structural Engineering, Intelligent Systems and Electrical Energy, ENSAM Casablanca, Morocco
}

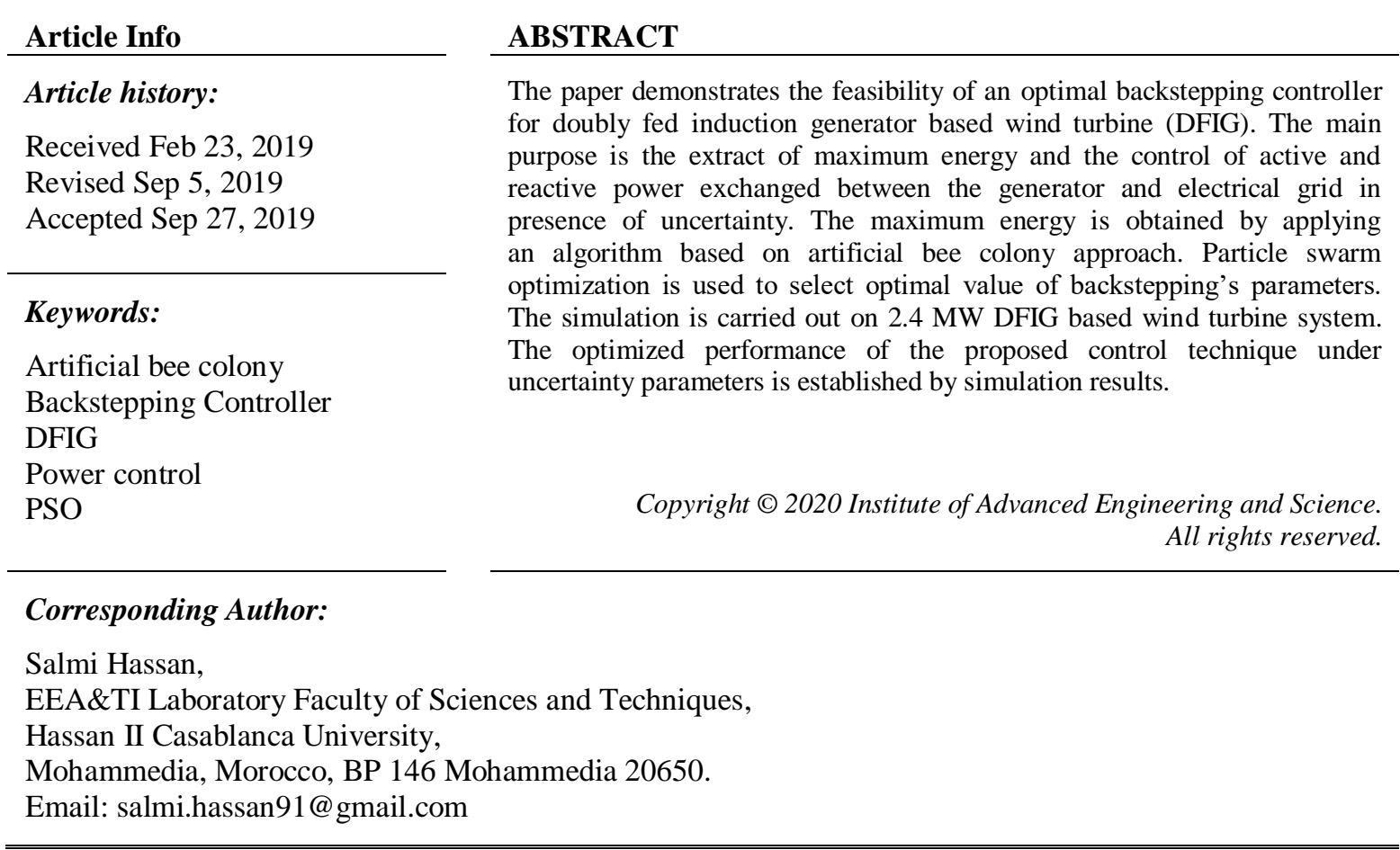

\section{INTRODUCTION}

The use of energy plays a vital role in making industrial and manufacturing process much more efficient. However, due to this large use, the production of unwanted materials that pollute air and contaminate soil and water was spawned an increase. In this way, the maximum rate of petroleum extraction has been reached and that subsequent methods of extraction cannot increase the rate further. One optimal solution to this problem is to use renewable energy sources. Their interest is that they do not emit greenhouse gases and produce no toxic and radioactive waste. Wind energy is one of the purest and eficient energy in the world for the production of electricity. The kinetic energy of wind is harnessed by wind turbines and converted into mechanical energy and finally into electrical energy.

Quite recently, a large variety of publications have been undertaken for doubly fed induction generator modeling and control, in which vector control combined with proportional-integral (PI) loops is widely used in industry, due to its simple architecture, big advantages of decoupling active and reactive power, in addition high efficiency [1]. The main purpose of DFIG control system is to efficiently extract the wind power whatever the weather conditions, this is usually named maximum power point tracking MPPT [2-3]. A substantial review of this control is given on [4]. Meanwhile, an approach to attenuate the impact of failures in DFIG generator based wind is often required, so that DFIG can withstand some typical disturbances wind system. However, the major deficient of vector control is that it cannot keep a high level performance when parameter's system vary as its PI parameters are fixed, while system nonlineaty on DFIG is strong resulted from the fact that is a typical time-varying dynamic system with parametric uncertainties. Many efficient parameters tunning methods have been proposed to enhance the PI controller, 
such as Fuzzy logic combined with PI which does not present the chattering phenomenon as the sliding mode controller [5-7].

In fact, the second order sliding has been used to regulate the wind turbine system in accordance with references provided by Maximum Power Point Tracking algorithm in [8]; in reference [9] a controller based on direct-current vector has been used in DFIG to extract the maximum energy and control the reactive power. The adaptive feedback linearization controller has been developed in [10]. A nonlinear predictive controller has been proposed to extract power and transient load reduction by using predictions of the output power to optimize the control of sequence in [11].

In the literature, several theories have been proposed to explain the effectiveness of backstepping control; in [12], a backstepping controller is developed for standalone DFIG to control the stator output voltage and fulfilling the demand energy variations and impact of wind velocity. In [13] the mechanical and electrical parts of the system are controller by rotor currents. In [14] the author's attention are not focused in regulating the mechanical part, they just apply the control strategies to the generator side converter by combining the feedback form of backstepping with two takagi-suggen fuzzy system. In [15], authors compares PI controller and backstepping approach for controlling independently the extracted active and reactive power from the stator of DFIG to electrical grid. In [16], electrical and mechanical parts are controlling by using stator currents as references.

For our knowledge, any paper has taken into consideration the impact of rapid variation of wind and DFIG's parameter uncertainty on the performance of controller. The objective of this paper is the control of active and reactive power extracted using backstepping control taking into consideration the DFIG's parameters variations which increases control efforts. Generally, the selection of backstepping's parameters is arbitrarily, in this work, we determine the best parameters of the backstepping controller by using particle swarm optimization (PSO). In addition, artificial bee colony (ABC) algorithm proposed in [17] is used to maximize the extracted power by adjusting the rotor speed, according to wind speed, without knowledge of system parameters.

\section{WIND TURBINE SYSTEM MODELING}

In this work, the considered system is a large variable speed wind turbine. Its architecture is shown in Figure 1. The most important parts of the system are composed of two components. The mechanical part is composed of a rotor entrained by kinetic energy of wind and a gearbox, which makes the high-speed shaft to the right. The electrical component contain a DFIG and converters.

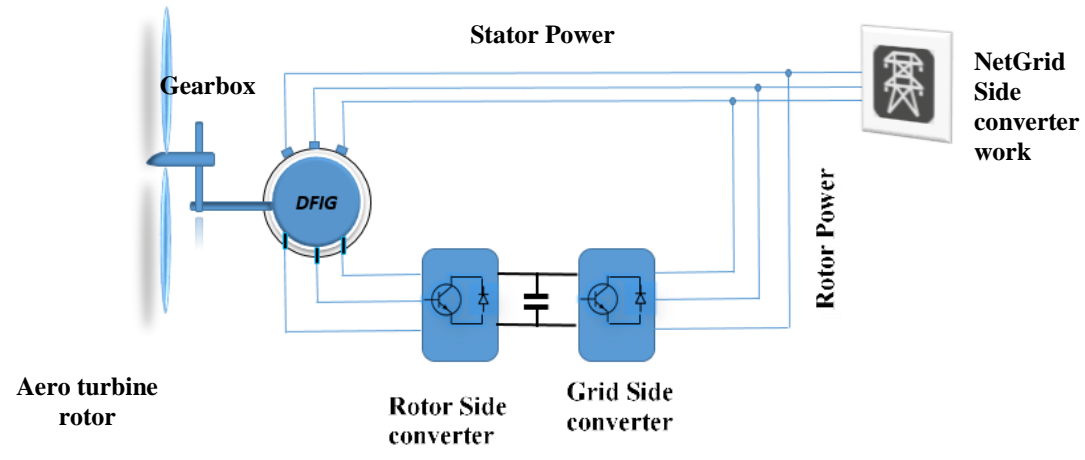

Figure 1. Architecture of wind turbine system (WTS)

\subsection{Mechanical model}

The mechanical power received by wind turbine system WTS is defined as:

$$
P_{t}=\frac{1}{2} \pi \rho R^{2} V^{3} C_{p}(\beta, \lambda)
$$

Where :

$\rho \quad:$ the air density $\left[\mathrm{Kg} / \mathrm{m}^{3}\right]$

$V \quad:$ The speed of wind $[\mathrm{m} / \mathrm{s}]$.

$\beta \quad$ : pitch angle.

$R \quad$ : the blade length [m]

$C_{p} \quad$ : the power coefficient

$\lambda \quad$ : tip speed ratio 
The relation between $C_{p}, \lambda$ and $\beta$ is defined by [18] :

$$
C_{p}(\lambda, \beta)=c_{1}\left(c_{2} \frac{1}{A}-c_{3} \cdot \beta-c_{4}\right) e^{-c_{5} \frac{1}{A}}+c_{6} \lambda
$$

With:

$$
\begin{aligned}
& c_{1}=0.5872, c_{2}=116, c_{3}=0.4, c_{4}=5, c_{5}=21, c_{6}=0.0085 . \\
& \frac{1}{A}=\frac{1}{\beta+0.08}-\frac{0.035}{1+\beta^{3}}
\end{aligned}
$$

The formula of the tip ratio is provided by:

$$
\lambda=\frac{\Omega_{t} R}{V}
$$

Where $\Omega_{t}$ is the rotor speed. Furthermore, the mechanical torque on the rotor is calculated by:

$$
C_{m}=\frac{P_{t}}{\Omega_{t}}=\frac{0.5 \pi \rho R^{3} V^{2} C_{p}(\beta, \lambda)}{\lambda}
$$

The mechanical angular speed and torque on the axis of generator DFIG is given by:

$$
\Omega_{g}=\mathrm{M} \Omega_{t} ; C_{g}=\frac{C_{m}}{M}
$$

$\mathrm{M}$ is the multiplication ratio.

In order to calculate the mechanical angular $\Omega_{g}$, we apply the fundamental equation of dynamic:

$$
\mathrm{J} \dot{\Omega}_{g}=C_{m}-\mathrm{M} C_{e}-\mathrm{f} . \Omega_{g} \mathrm{~J}=J_{r}+M^{2} J_{g}
$$

Where $\mathrm{J}$ is the total rotational inertia and $C_{e}$ is electromagnetic torque. The damping coefficient $\mathrm{f}$ is overlooked because it is lowest than rotational inertia [19]. Therefore, the mathematic equation which model our system is:

$$
\mathrm{J} \dot{\Omega}_{g}=C_{m}-\mathrm{M} C_{e m} \rightarrow \dot{\Omega_{g}}=\frac{0.5 \pi \rho R^{3} V^{2} C_{P}{ }^{\max }}{J M^{3} \lambda_{o p t}{ }^{3}} \Omega_{g}{ }^{2}-\frac{M C_{e m}}{J}
$$

\subsection{Electrical model}

The electrical model of the DFIG in dq reference are given by [3]:

$$
\begin{aligned}
& u_{d s}=R_{s} i_{d s}+\frac{d}{d t} \phi_{d s}-\omega_{s} \phi_{q s} u_{q s}=R_{s} i_{q s}+\frac{d}{d t} \phi_{q s}-\omega_{s} \phi_{d s} \\
& u_{d r}=R_{r} i_{d r}+\frac{d}{d t} \phi_{d r}-\omega_{s} \phi_{q r} u_{q r}=R_{r} i_{q r}+\frac{d}{d t} \phi_{q s}-\omega_{r} \phi_{d r}
\end{aligned}
$$

With:

$$
\begin{aligned}
& \omega_{r}=\omega_{s}-\mathrm{P} \Omega \mathrm{g} \\
& \phi_{d s}=L_{s} i_{d s}+\mathrm{M} i_{d r} \phi_{q s}=L_{s} i_{q s}+\mathrm{M} i_{q r} \phi_{d r}=L_{r} i_{d r}+\mathrm{M} i_{d s} \phi_{q r}=L_{r} i_{q r}+\mathrm{M} i_{q s}
\end{aligned}
$$

With:

$$
L_{s}=l_{s}-M_{s} \text { and } L_{r}=l_{r}-M_{r}
$$

$L_{s}, L_{r} \quad$ rotor and stator cyclic inductances $M_{s}, M_{r}$ : Mutual inductances;

$l_{s}, l_{r}: \quad$ stator and rotor inductances. $\mathrm{M}=\operatorname{Max}\left(M_{s}, M_{r}\right)$. 
The electromagnetic torque and power equations at the stator are expressed by [20]:

$$
C_{e m}=\frac{3}{2} * \mathrm{p}^{*}\left(\phi_{q s} i_{d s}-\phi_{d s} i_{q s}\right) P_{\text {stator }}=\frac{3}{2}\left(u_{d s} i_{d s}+u_{q s} i_{q s}\right) Q_{\text {stator }}=\frac{3}{2}\left(u_{q s} i_{d s}-u_{d s} i_{q s}\right)
$$

\section{POWER CAPTURE OPTIMIZATION}

The evolution of the power extracted from a wind turbine according to the speed of the wind is presented in the Figure 2.

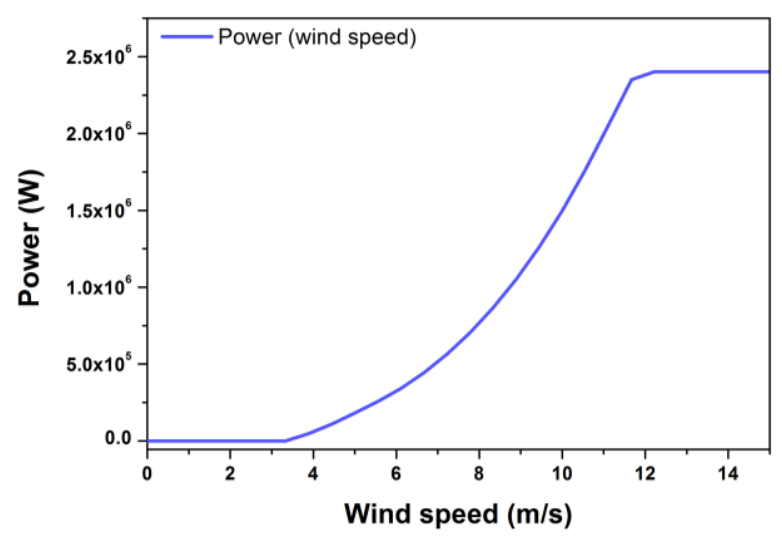

Figure 2. Wind power depending on the wind

As shown in Figure 2, the system is designed to operate with a specific interval of wind speed. The limit of the range are known as the lower speed $V_{c u t}$ and top speed $V_{\text {cout }}$. In this interval, the controller must optimize the power extracted. This extracted power is usually dependent on the value of $C_{p}$, which must be set at its optimum value $C_{p_{\text {opt }}}$. Therefore, $\beta$ and $\lambda$ must be optimal.

$$
\lambda=\lambda_{o p t} ; \beta=\beta_{o p t} .
$$

In order to fix an optimal tip speed ratio, the rotational speed $\omega_{t}$ of the rotor must follow the optimal value

$$
\omega_{\text {opt }} \text { value: } \omega_{o p t}=\frac{\lambda_{o p t}}{R} v
$$

Most of the previous studies have not consider wind speed turbulence which increases control efforts. In this paper, a compromise between power capture efficiently and load reduction is obtained by a suitable selection of the controller bandwith.

\section{POWER CONTROL APPROACH}

The principal objective of the proposed control is capturing the maximum power of the incident energy of the system by adjusting the rotational speed, and control the active and reactive power of the system with large inertia exchanged between (DFIG) and the grid in presence of parameter's uncertainty such as resistance, inductance and tip speed ratio variations.

\subsection{Maximum power point tracking (MPPT)}

The MPPT algorithm is employed on region between Vcut and Vcout to capture maximum power point (MPP) for all wind speeds. In the literature, several MPPT algorithms have been discussed so far [21]. These methods are effective for wind turbine with low inertia. But, for high inertia, it takes more time and don't offer effective results. According to (1), whatever the wind speed, the maximum power extracted is obtained when power coefficient is optimum Figure 3. 


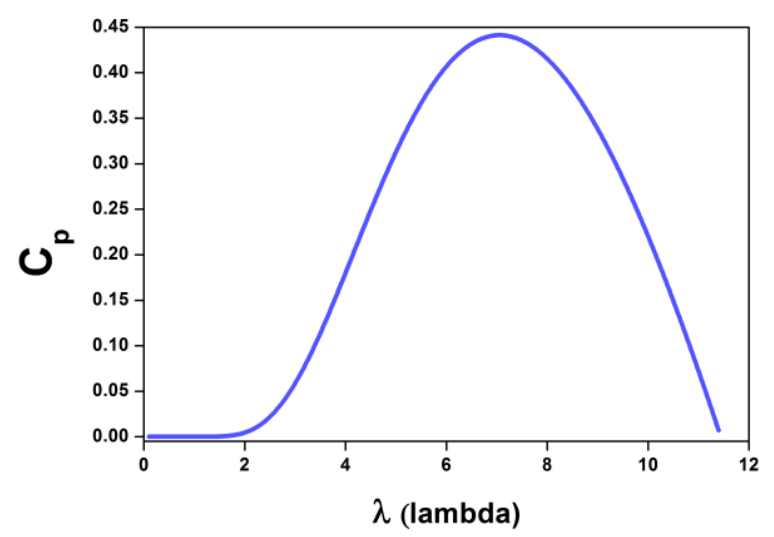

Figure 3. Power coefficient for a specific wind turbine

In this paper, a novel solution to MPPT based on Artificial bee colony algorithm [22] under variable wind speeds. Only one other study [23], to our knowledge, has come up with ABC based MPPT but without taking into account wind speed turbulence. The ABC algorithm includes three main groups: employed, onlooker and scouts. Each group has a well-defined role [17]. Employed bee exploits the food sources and carry the food source back to the hive. They share these foods with the onlooker bees by dancing in the designated dance area inside the hive. The onlooker bees select the optimal food. All food sources exploited fully, will be abandoned by employee bees and become scout. The process of the ABC algorithm is established in [17]. In this paper, with Artificial Bee colony (ABC), we determine the reference value of rotor speed $\Omega^{r e f}$ that should be applied to extract the maximum power. To concretize the control of Artificial Bee Colony based MPPT, each bee is defined as the rotational speed and the output power of system as the nectar amount. The initial rotor speed will become:

$$
\Omega_{i}=\Omega_{\text {min }}+\operatorname{rand}(0,1) *\left(\Omega_{\max }-\Omega_{\min }\right)
$$

New solution: new

$$
-\Omega_{i}=\Omega_{i}+\operatorname{\phi i}\left(\Omega_{i}-\Omega_{k}\right)
$$

The fitness of each candidate is assessed by its generated output active power:

$$
\mathrm{Pi}=\frac{P_{m i}}{\sum_{i}^{s n} P i}
$$

The detail of the ABC algorithm used in this paper to determine the optimal speed is below:

- Insert the maximum cycle MCN and number of initial candidate SN.

- Generate randomly the rotor speed (employed bees) (18)

- Calculate the power of each rotor speed (1).

- Repeat:

- Modify the rotor speed according to (19).

- Evaluate the power of the new solution (1)..

- Apply the greedy selection for each rotor speed.

- Evaluate the probability according to (20).

- fix the onlooker bees basing on the probability and edit each candidate (18)

- Apply the greedy selection for each onlooker bees.

- Fix the scouts bees and replace it by (18).

- Memorize the optimal solution

- Increment the cycle until Maximum cycle MCN.

\subsection{Electrical part}

According to (8), the nonlinearity of the generator's model is due to the coupling between the rotor speed and the currents. We annul the direct axis current $i_{d}$ in order to align flux $\phi_{s}$ in d-axis [24]. We obtain: 


$$
\phi_{s d}=\phi_{s} ; \phi_{s q}=0
$$

Therefore from (10), we obtain:

$$
\begin{aligned}
& i_{d s}=-\frac{M}{L_{S}} i_{d r}+\frac{\phi_{s d}}{L_{S}} \\
& i_{q s}=-\frac{M}{L_{S}} i_{q r}
\end{aligned}
$$

In addition, we notice that stator is connected to a stable grid,therfore stator resistive is neglected and the stator equation are reduced to:

$$
\begin{gathered}
u_{d s}=R_{s} i_{d s} \\
u_{q s}=R_{s} i_{q s}-\omega_{s} \phi_{d s}
\end{gathered}
$$

The stator powers can be expressed a:

$$
\begin{aligned}
& P_{S}=\frac{-3 M}{2 L_{S}} V_{S q} I_{r q} \\
& Q_{S}=\frac{-3 M}{2 L_{S}} V_{S q} I_{r d}+\frac{3}{2 L_{S} \omega_{S}} V_{S q}{ }^{2}
\end{aligned}
$$

The double fed induction generator is controlled by rotor voltage. Therefore we should set the relation between currents and voltages of rotor circuit:

$$
V_{r d}=R_{r} I_{r d}+\sigma L_{r} I_{r d^{-}}^{\cdot} \omega_{r} \sigma L_{r} I_{r q} V_{r q}=R_{r} I_{r q}+\sigma L_{r} I_{r q}^{\cdot}+\omega_{r} \sigma L_{r} I_{r d}+\omega_{r} \frac{L_{m} V_{s q}}{L_{s} \omega_{s}} . \text { Where } \sigma=\frac{L_{r} L_{s}-M^{2}}{L_{r} L_{s}}
$$

The faults in DFIG are dominated by stator and rotor winding insulation faults, short circuits in stator circuit, variable resistance faults, cracked rotor end rings ....

Equations. (7) and (27) end up:

$$
\begin{aligned}
& \dot{\Omega_{g}}=\frac{0.5 \pi \rho R^{5} C_{P}{ }^{\max }}{J M^{3} \lambda_{o p t}{ }^{3}} \Omega_{g}{ }^{2}-\frac{M C_{e m}}{J}+\frac{0.5 \pi \rho R^{5}}{J M^{3}}\left(\frac{\Delta C_{P}}{\lambda_{o p t}{ }^{3}}+3 \frac{C_{P} \Delta \lambda}{J \lambda_{o p t}{ }^{4}}\right) \Omega_{g}{ }^{2} \\
& I_{r d}^{\cdot}=-\frac{\left(L_{r}+\Delta L_{r}\right)\left(L_{S}+\Delta L_{S}\right)}{\left(L_{r}+\Delta L_{r}\right)\left(L_{S}+\Delta L_{S}\right)-(M+\Delta M)^{2}} \frac{\left(R_{r}+\Delta R_{r}\right)}{\left(L_{r}+\Delta L_{r}\right)} * I_{r d}+\left(\omega_{r}-P \Omega_{g}\right) I_{r q} \\
& +\frac{\left(L_{r}+\Delta L_{r}\right)\left(L_{S}+\Delta L_{S}\right)}{\left(L_{r}+\Delta L_{r}\right)\left(L_{S}+\Delta L_{s}\right)-(M+\Delta M)^{2}} \frac{1}{\left(L_{r}+\Delta L_{r}\right)} * V_{r d} \\
& I_{r q}=-\frac{\left(L_{r}+\Delta L_{r}\right)\left(L_{S}+\Delta L_{S}\right)}{\left(L_{r}+\Delta L_{r}\right)\left(L_{S}+\Delta L_{S}\right)-(M+\Delta M)^{2}} \frac{\left(R_{r}+\Delta R_{r}\right)}{\left(L_{r}+\Delta L_{r}\right)} * I_{r q}+ \\
& \left(\omega_{s}-P \Omega_{g}\right) I_{r d}-\left(\omega_{S}-P \Omega_{g}\right) \frac{\left(L_{r}+\Delta L_{r}\right)\left(L_{S}+\Delta L_{S}\right)}{\left(L_{r}+\Delta L_{r}\right)\left(L_{S}+\Delta L_{S}\right)-(M+\Delta M)^{2}} * \frac{L_{m}}{\left(L_{r}+\Delta L_{r}\right) \omega_{S\left(L_{S}+\Delta L_{S}\right)}} \\
& * V_{s q}+\frac{\left(L_{r}+\Delta L_{r}\right)\left(L_{S}+\Delta L_{S}\right)}{\left(L_{r}+\Delta L_{r}\right)\left(L_{S}+\Delta L_{S}\right)-(M+\Delta M)^{2}} \frac{1}{\left(L_{r}+\Delta L_{r}\right)} * V_{r q}
\end{aligned}
$$

Where $\Delta R_{r}, \Delta L_{r}, \Delta L_{s}, \Delta M, \Delta \lambda$ and $\Delta C_{P}$ are the rotor resistance and inductance variation, the stator resistance and inductance variation, and discrepancy in the calculation of $\lambda_{O P T}$ and $C_{P}$, respectively. By using partial derivative, we obtain:

$$
\begin{aligned}
& \dot{\Omega_{g}}=\frac{0.5 \pi \rho R^{5} C_{P} \max }{J M^{3} \lambda_{o p t}} \Omega_{g}{ }^{2}-\frac{M C_{e m}}{J}+\Delta 1 I_{r d}=-\frac{R_{r}}{L_{r} \sigma} I_{r d}+\omega_{r} I_{r q}+\frac{1}{\sigma L_{r}} V_{r d}+\Delta 2 \\
& \dot{I_{r q}}=-\frac{R_{r}}{L_{r} \sigma} I_{r q}-\omega_{r} I_{r d}-\omega_{r} \frac{M}{\omega_{s} \sigma L_{r} L_{s}} V_{s q}+\frac{1}{L_{r} \sigma} V_{r q}+\Delta 3
\end{aligned}
$$

With:

$$
\begin{aligned}
& \boldsymbol{\Delta} 1=\frac{0.5 \pi \rho R^{5}}{J M^{3}}\left(\frac{\Delta C_{P}}{\lambda_{o p t}{ }^{3}}+3 \frac{C_{P} \Delta \lambda}{J \lambda_{o p t}}\right) \Omega_{g}{ }^{2} \\
& \boldsymbol{\Delta} 2=\left(\frac{\Delta L_{r} * R_{r}}{\sigma^{2} * L_{r}{ }^{2}}+\frac{\Delta R_{r}}{\sigma L_{r}}+\frac{\Delta L_{s} * R_{r}}{\sigma L_{r} L_{S}}+\frac{\Delta L_{S} * R_{r}}{\sigma^{2} L_{r} L_{S}}+\frac{2 * \Delta M * M * R_{r}}{\sigma^{2} L_{r} L_{S}}\right) I_{r d}+\left(\frac{\Delta L_{r}}{\sigma^{2} * L_{r}{ }^{2}}+\frac{\Delta L_{s}}{\sigma L_{r} L_{S}}+\frac{\Delta L_{S}}{\sigma^{2} L_{r} L_{S}}+\frac{2 * \Delta M * M}{\sigma^{2} L_{r} L_{s}}\right) V_{r d}
\end{aligned}
$$




$$
\begin{aligned}
& \Delta 3=\left(\frac{\Delta L_{r} * R_{r}}{\sigma^{2} * L_{r}^{2}}+\frac{\Delta R_{r}}{\sigma L_{r}}+\frac{\Delta L_{s} * R_{r}}{\sigma L_{r} L_{S}}+\frac{\Delta L_{s} * R_{r}}{\sigma^{2} L_{r} L_{s}}+\frac{2 * \Delta M * M * R_{r}}{\sigma^{2} L_{r} L_{s}}\right) I_{r q}+\left(\frac{\Delta L_{r}}{\sigma^{2} * L_{r}{ }^{2}}+\frac{\Delta L_{s}}{\sigma L_{r} L_{s}}+\frac{\Delta L_{s}}{\sigma^{2} L_{r} L_{s}}+\frac{2 * \Delta M * M}{\sigma^{2} L_{r} L_{s}}\right) V_{r q}+ \\
& \left(\frac{\Delta L_{s} * \omega_{r} M}{\omega_{s} * \sigma^{2} * L_{r} * L_{s}{ }^{2}}+\frac{\Delta L_{r} * \omega_{r} * M}{\omega_{s} * \sigma^{2} * L_{s} * L_{r}{ }^{2}}\right) V_{s q}
\end{aligned}
$$

\subsection{Application of backstepping controller in double fed induction generator}

The studied system (31) is nonlinear; the linearization around operating point cannot be employed to design the controller. Therfore, we must apply one of the existing nonlinear control design. One of these methods, we use the nonlinear backstepping controller. The nonlinear Backstepping approach is a method that can efficiently linearize a complex nonlinear system in the presence of parameter's uncertainties. The essence of this method consists the decomposing of the system into many subsystems, design the Lyapunov function and virtual function for each subsystem. Therefore, it uses an error variable that can be stabilized by choosing the optimized control based on the study of lyapunov stability. Taking into account that the variation of parameters $\Delta R_{s}, \Delta L_{s}, \Delta L_{r}, \Delta M, \Delta C_{P}$ and $\Delta \lambda$ are finite. Therefore, the function $\Delta 1, \Delta 2$ and $\Delta 3$ are bounded: $\left|\Delta_{1}\right| \leq \rho_{1} ;\left|\Delta_{2}\right| \leq \rho_{2} ;\left|\Delta_{3}\right| \leq \rho_{3}$

\section{Step1:}

In order to force the generator angular speed at the desired reference $\Omega_{g}{ }^{r e f}$ and stabilize the error dynamic, we define the positive lyapunov function:

$$
V_{\Omega}=0.5 e_{\Omega}^{2}
$$

The error tracking is defined as:

$$
e_{\Omega}=\Omega_{g}-\Omega_{g}^{r e f}
$$

The derivative of this function is:

$$
\dot{V}_{\Omega}=e_{\Omega} * \dot{e_{\Omega}}=e_{\Omega}\left(\frac{0.5 \pi \rho R^{5} C_{P}{ }^{\max }}{J M^{3} \lambda_{o p t}{ }^{3}} \Omega_{g}{ }^{2}-\frac{M C_{e m}}{J}+\Delta 1-\Omega_{g}{ }^{r e f}\right)
$$

In order to guarantee $\Omega_{g}$ tracks $\Omega_{g}{ }^{r e f}$, the derivative must be always negative. Therefore, $C_{e m}{ }^{r e f}$ must be chosen as:

$$
C_{e m}^{r e f}=\frac{0.5 \pi \rho R^{5} C_{P}{ }^{m a x}}{M^{3} \lambda_{\text {opt }}{ }^{3}} \Omega_{g}{ }^{2}-\frac{M T_{e}}{J}+\Delta 1-\mathrm{J} \Omega_{g} \dot{r}^{r} f+J K_{1} e_{\Omega}+\mathrm{J} y_{1} \operatorname{sign}\left(e_{\Omega}\right)
$$

With $y_{1} \geq \rho_{1}$

$K_{1}$ is the feedback gain. This choice makes $\dot{V}_{\Omega}$ negative.

After calculation of electromagnetic torque, the quadrature rotor current reference are:

$$
I_{r q}{ }^{r e f}=-\frac{L_{s}}{P M \phi_{s}}\left(\frac{0.5 \pi \rho R^{5} C_{P}{ }^{\max }}{M^{3} \lambda_{o p t}{ }^{3}} \Omega_{g}{ }^{2}-\mathrm{J} \Omega_{g}{ }^{\dot{r} e f}+J K_{1} e_{\Omega}+\mathrm{J} y_{1} \operatorname{sign}\left(e_{\Omega}\right)\right)
$$

To maintain a unit power factor, the reactive power should be fixed at zero: $Q_{S}=0$ From (19), we obtain:

$$
I_{r d}^{r e f}=\frac{V_{s q}}{M \omega_{s}}
$$

Step2:

The calculation of rotor voltage is primary to force the currents follow $I_{r q}{ }^{r e f}$ and $I_{r d}{ }^{r e f}$ The lyapunov function is

$$
V=0.5 e_{\Omega}^{2}+0.5 e_{r d}^{2}+0.5 e_{r q}^{2}
$$

Where

$$
e_{r d}=I_{r d}-I_{r d}^{r e f} e_{r q}=I_{r q}-I_{r q}^{r e f}
$$


The derivative of lyapunov function is:

$$
\begin{aligned}
& \dot{V}=e_{\Omega} * \dot{e_{\Omega}}+e_{r d} * e_{r d}^{\dot{1}}+e_{r q} * e_{r q}^{\cdot}=-K_{1} e_{\Omega}^{2}-\left(y_{1}-\rho_{1}\right)\left\|e_{\Omega}\right\|+e_{r d} *\left(-\frac{R_{r} I_{r d}}{L_{r} \sigma}+\omega_{r} I_{r q}+\frac{1}{\sigma L_{r}} v_{r d}+\Delta_{2}-\right. \\
& \left.I_{r d}{ }^{d}\right)+e_{r q} *\left(-\frac{R_{r} I_{r q}}{L_{r} \sigma}-\omega_{r} I_{r d}-\omega_{r} \frac{M}{\omega_{s} \sigma L_{r} L_{s}} v_{s q}+\frac{1}{\sigma L_{r}} v_{r q}+\Delta_{3}-I_{r q}{ }^{d}\right)
\end{aligned}
$$

By taking the following control $V_{r d}$ and $V_{r q}$ :

$$
\begin{aligned}
& V_{r d}=\sigma L_{r}\left[-K_{2} e_{r d}-y_{2} \operatorname{sign}\left(e_{r d}\right)+\frac{R_{r} I_{r d}}{L_{r} \sigma}-\left(\omega_{s}-P \Omega_{g}\right) I_{r q}+I_{r d}^{\cdot r e f}\right] \\
& V_{r q}=\sigma L_{r}\left[-K_{3} e_{r q}-y_{3} \operatorname{sign}\left(e_{r q}\right)+\frac{R_{r} I_{r q}}{L_{r} \sigma}+\left(\omega_{s}-P \Omega_{g}\right) I_{r d}+I_{r q}^{\cdot r e f}+\right. \\
& \left.\left(\omega_{s}-P \Omega_{g}\right) \frac{M}{\omega_{s} \sigma L_{r} L_{s}} V_{s q}\right]
\end{aligned}
$$

With $K_{2}$ and $K_{3}$ are feedback gain. We obtain

$$
\dot{V} \leq-K_{1} e_{\Omega}{ }^{2}-\left(y_{1}-\rho_{1}\right)\left\|e_{\Omega}\right\|-K_{2} e_{r d}{ }^{2}-K_{3} e_{r q}{ }^{2}-y_{2}\left\|e_{r d}\right\|-y_{3}\left\|e_{r q}\right\|+\left\|e_{r d}\right\| \Delta_{2}+\left\|e_{r q}\right\| \Delta_{3}
$$

Which implies that our system is asymptotically stable.

The choice of $K_{1}, K_{2}$ and $K_{3}$ is heuristic, for these we propose the PSO method to determine these parameters.

\section{RESULTS AND SIMULATION}

The simulation is realized in MATLAB/Simulink with the parameters of a $2.4 \mathrm{MW}$ machine. In order to verify asymptotic stability of our controller and show its performance, we implemented the system that includes wind turbine, (DFIG) and converter. The simulation has been realized for a wind speed from $6 \mathrm{~m} / \mathrm{s}$ to $12 \mathrm{~m} / \mathrm{s}$ as shown in Figure 4. Table 1 shows the parameters of the DFIG based wind turbine. In this paper, PSO is used to select efficient parameters of controller in order to converge rapidly to the optimal functioning. PSO algorithm introduced by Kennedy and Eberhart in 1995 [24], is inspired by social behavior of bird flocking or fish schooling, characterized as a simple structure. PSO algorithms use particles which represent potential solutions of the problem. It is first initialized with a group of random particles. In each iteration, every solution is modified at a certain velocity by following two best solutions (fitness). The personal best $P_{\text {best }}$ which is the best value achieved by each solution and the global best $g_{\text {best }}$ is the best value of all particles.

The position $X_{i}$ and the velocity $Y_{i}$ of each particle of the population are defined as the following two equations:

$$
Y_{i+1}=\omega \cdot Y_{i}+c_{1} \cdot r_{1}\left(P_{b e s t}-X_{i}\right)+c_{2} \cdot r_{2}\left(g_{b e s t}-X_{i}\right)(41) X_{i+1}=Y_{i+1}+X_{i}
$$

Where $Y_{i}$ is the velocity of the particle, $X_{i}$ is the solution. $r_{1}$ and $r_{2}$ are random numbers. $c_{1}$ and $c_{2}$ are usually between 1.5 and 2.5 and finally $\omega$ is the inertia factor.

The PSO algorithm used in this paper consists of the following steps:

1. Population of particles is generated with random position and velocities (parameters $k_{1}, k_{2}, k_{3}$ of backstepping controller) (population size 50).

2. The fitness of each candidate solution is generated (40 and 25)

3. Select the $P_{\text {best }}$ and $g_{\text {best }}$.Firt iteration:

4. Velocity updating : the velocities of all particles are edited according to equation of $Y_{i+1}$

5. Position updating: the position of all particles are updated according to the (42)

6. Evaluate the fitness of each new individual

7. Compare the new individual with $P_{\text {best }}$ and $g_{\text {best }}$.

8. Go back to step 4 until final iteration (maximum of iterations is 15 )

9. Finally, the optimal position will be the solution of optimization problem.

In order to converge rapidly to the best solution, we minimize a certain criterion such as the mean square error can be calculated by the following equation: 
Mean square error $=\frac{1}{N T} \sum_{i=1}^{N}\left(e_{\Omega}^{2}+e_{r d}^{2}+e_{r q}^{2}\right)$

$\mathrm{N}$ is the total number of samples, $\mathrm{T}$ : the sampling time

Table 1. The parameters of the system

\begin{tabular}{c|ccc}
\hline PARAMETERS & NUMERICAL VALUE & PARAMETERS & NUMERICAL VALUE \\
\hline $\boldsymbol{L}_{\boldsymbol{r}}$ & $0.0026 \mathrm{H}$ & Multiplication ratio M & 100 \\
$\boldsymbol{R}_{\boldsymbol{r}}$ & $0.0029 \Omega$ & $\boldsymbol{\rho}$ & $1.225 \mathrm{Kg} / \mathrm{m}^{3}$ \\
$\boldsymbol{L}_{\boldsymbol{S}}$ & $0.0026 \mathrm{H}$ & Blade length (R) & 42 \\
$\boldsymbol{R}_{\boldsymbol{S}}$ & $0.0021 \Omega$ & Number of pairs poles (p) & 2 \\
$\mathrm{Lm}$ & $0.0025 \mathrm{H}$ & Coefficient of the viscous damping (f) & $0.01 \mathrm{~N} \mathrm{~m} / \mathrm{rad} \mathrm{s}$ \\
\hline
\end{tabular}
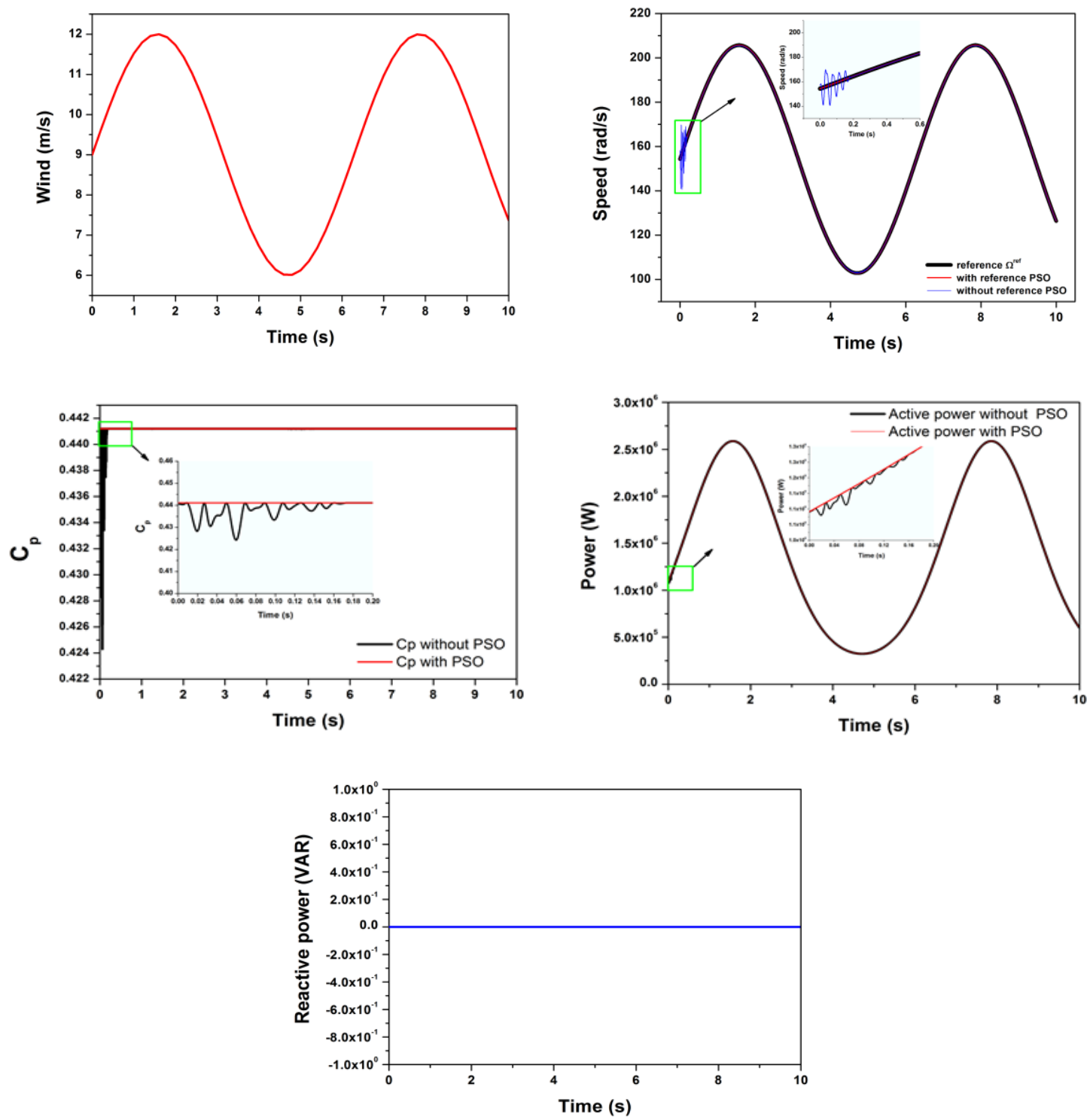

Figure 4. Simulation without parameters variation

The determination of speed reference $\Omega^{r e f}$, which tracks the speed of the wind is given by Artificial Bee colony algorithm and then used by backstepping controller to regulate the speed of DFIG. The schematic of our control strategy is given in Figure 5. 


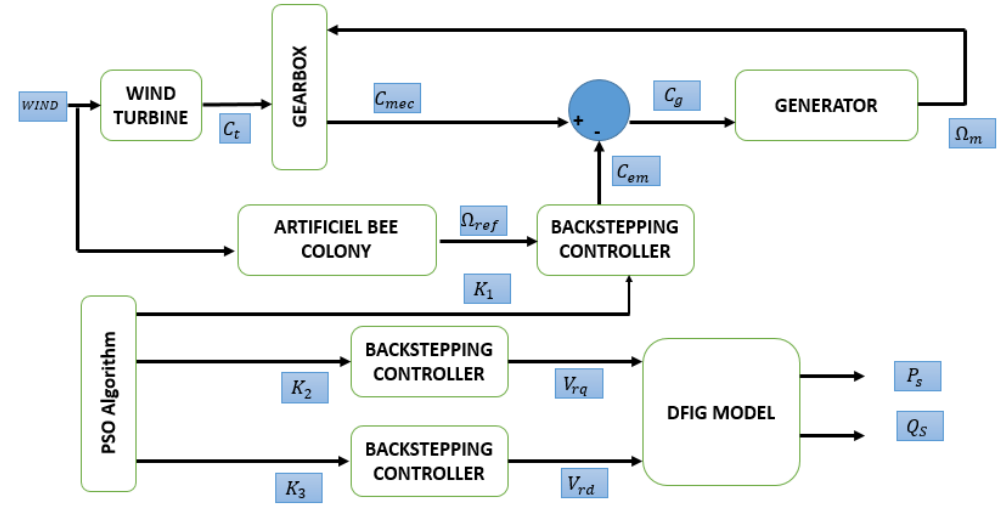

Figure 5. Schematic of control strategy

To verify the robustness of this proposed controller, PSO-Backstepping is compared with arbitrary backstepping controller which is implemented on recent works [26-29]. Figure 4 shows the simulation results without parameters variations and the zoom of these resultants, respectively. Based on the results, it can be seen that the rotor speed $\Omega$, active power $\mathrm{P}$ and reactive power $\mathrm{Q}$ converge to their references with a precision rate.in addition, the power coefficient is optimal $(\mathrm{Cp}=0,44)$, which indicates that the power extracted from the system is maximal. However, the backstepping controller with optimal parameters $\left(K_{1}, K_{2}\right.$ and $K_{3}$ ) based on PSO algorithm permits to converge more quickly to the optimal trajectory than the backstepping with parameters selected arbitrary. In order to evaluate the robustness of our controller with presence of uncertainty, we have considered $\Delta L_{r}=\Delta L_{S}=\Delta M=5 \%, \Delta R_{r}=90 \%, \Delta C_{P}=6 \%$ and $\Delta \lambda=5 \%$. It can be seen in Figure 6 that the robustness of our proposed controller does not affected by the variation of DFIG's parameters and the speed $\Omega$, active power $\mathrm{P}$ and reactive power $\mathrm{Q}$ converge to their optimal values. In addition, the particle swarm optimization selects the best value of parameters for tracking rapidly the best trajectory.
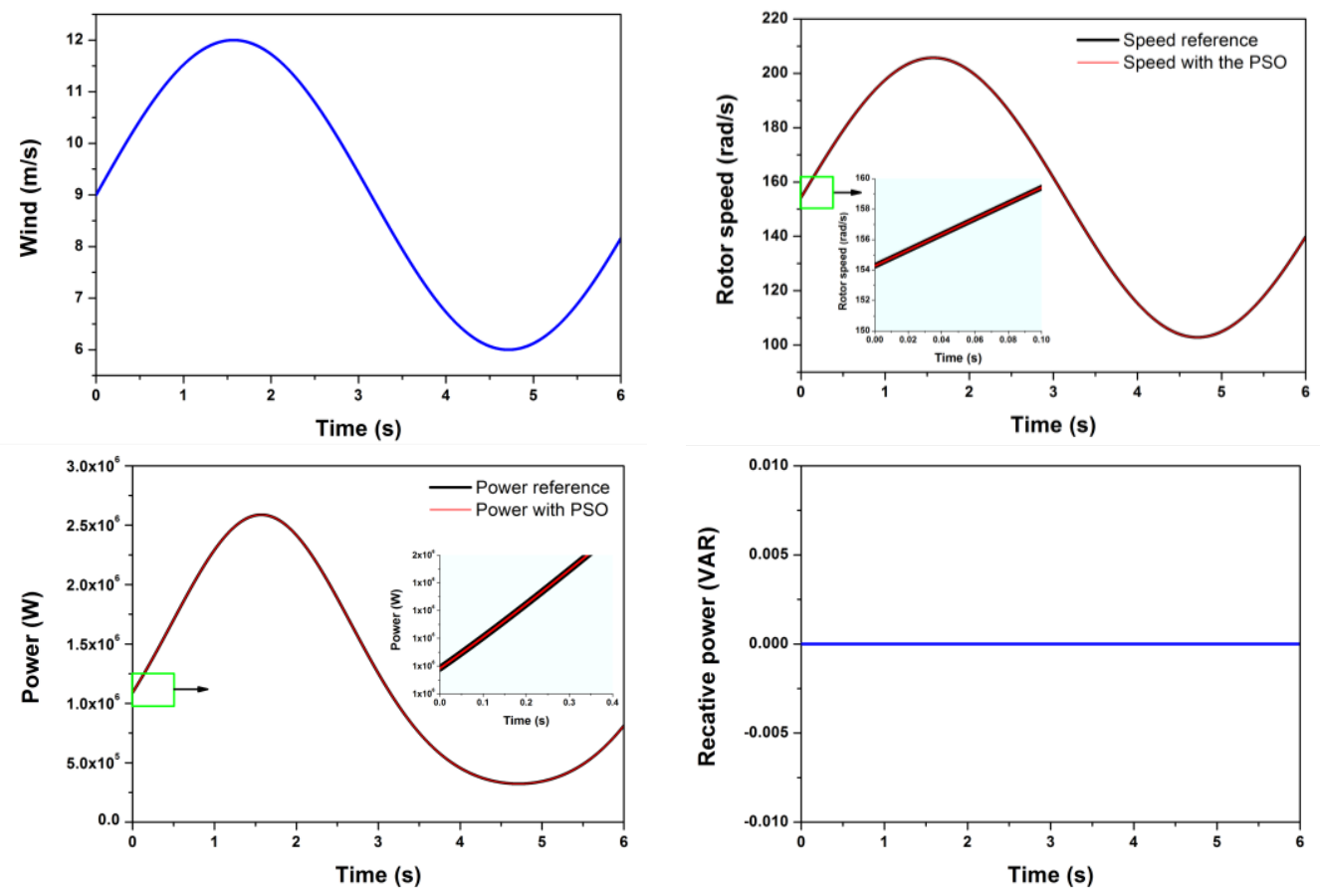

Figure 6. Simulation with parameters variation 


\section{CONCLUSION}

From the outcome of our investigation, it is possible to conclude that the backstepping controller with particle swarm optimization can solve the challenge of controlling the power extracted in presence of DFIG's parameters uncertainties, which is due to technical problem in the generator. The ABC algorithm is applied to select the reference of rotational speed of wind turbine whatever the wind in order to extract the maximum power in real time. The robustness of the controller is demonstrated by simulation results.

\section{ACKNOWLEDGEMENTS}

This work returns the framework of the research project SISA1 "Mini intelligent Power plant" between research center SISA and our University. We are anxious to think the Hassan II University of Casablanca for the financing of this project.

\section{REFERENCES}

[1] Li SH, Haskew TA, Williams KA, Swatloski RP, "Control of DFIG wind turbine with direct-current vector control configuration," IEEE Trans Sustain Energy, vol. 3(1), pp. 1-11, 2012.

[2] D. Kumar et K. Chatterjee, "A review of conventional and advanced MPPT algorithms for wind energy systems," Renewable and Sustainable Energy Reviews, vol. 55, pp. 957-970, Mar. 2016.

[3] Lab-Volt Ltd., "Principles of doubly fed induction generators (DFIG)," Renewable energy, 2011.

[4] Hoang thinh do, Tri Dung Dang, Hoai Vu Anh Truong, Kyoung Kwan Ahn, "Maximum power point tracking and output power control on pressure coupling wind conversion system," IEEE Transactions on Industrial Electronics, vol. 65(2), Feb. 2018.

[5] C. Eddahmani, "A Comparative Study of Fuzzy Logic Controllers for Wind Turbine Based on PMSG," International Journal of Renewable Energy Research (IJRER), vol. 8(3), pp. 1386-1392, sep. 2018.

[6] S. Kahla, Y. Soufi, M. Sedraoui, and M. Bechouat, "Maximum Power Point Tracking of Wind Energy Conversion System Using Multi-objective grey wolf optimization of Fuzzy-Sliding Mode Controller," Int. J. Renew. Energy Res. IJRER, vol. 7(2). pp. 926-936, Jun. 2017.

[7] M. Emna and K. Adel, "An Adaptive Backstepping Flux Observer for two Nonlinear Control Strategies Applied to WGS based on PMSG," Int. J. Renew. Energy Res. IJRER, vol. 6(3), pp. 914-929, Sep. 2016.

[8] B. Beltran, M. E. H. Benbouzid and T. Ahmed-Ali, "Second-Order Sliding Mode Control of a Doubly Fed Induction Generator Driven Wind Turbine," in IEEE Transactions on Energy Conversion, vol. 27(2), pp. 261-269, Jun. 2012.

[9] S. Li, T. A. Haskew, K. A. Williams and R. P. Swatloski, "Control of DFIG Wind Turbine With Direct-Current Vector Control Configuration," in IEEE Transactions on Sustainable Energy, vol. 3(1), pp. 1-11, Jan. 2012.

[10] Mullane, A., Lightbody, G., Yacamini, R., "Adaptive control of variable speed wind turbines," Rev. Energ. Ren. Power Eng, pp. 101-110, 2001.

[11] A. Bektache, B. Boukhezzar, "Nonlinear predictive control of a DFIG-based wind turbine for power capture optimization," International journal of electrical power \& Energy systems, vol. 101, pp. 92-102, 2018.

[12] N. Bouchiba, A. Barkia, S. Sallem, L. Chrifi-Alaoui, S. Drid and M. Kammoun, "A real-time Backstepping control strategy for a doubly fed induction generator based wind energy conversion system," 2017 6th International Conference on Systems and Control (ICSC), Batna, 2017, pp. 549-554.

[13] Elmansouri, A., Elmhamdi, J., Boualouch, A., "Control by back stepping of the DFIG used in the wind turbine," Int. J.Emerg. Technol. Advanced Eng, vol. 5, pp. 472-478, 2015.

[14] Aounallah Tarek, Essounbouli Najib, Hamzaoui Abdelaziz, Bouchafaa Farid, "Algorithm on fuzzy adaptive backstepping control of fractional order for doubly-fed induction generators," IET Renewable Power Generation, vol. 12(8), pp. 962-967, 2018.

[15] Mohamed Nadour, Ahmed Essadki, Tamou Nasser, "Comparative analysis between PI \& Backstepping control strategies of DFIG driven by wind turbine," International journal of Renewable Energy Research, vol. 7(3), 2017.

[16] Bossoufi, B., Karim, M., Lagrioui, A., Taoussi, M., Derouich, A., "Adaptive backstepping control of DFIG generators for variable-speed wind turbines system," J. Elect. Syst, vol. 10, pp. 317-330, 2014.

[17] Hassan Salmi, Abdelmajid Badri, Mourad Zegrari, Aicha Sahel and Abdennaceur Baghdad, "Artificial Bee Colony MPPT control of Wind Generator without speed Sensors", International Conference on Electrical and Information Technologies, ICEIT, 2017.

[18] Mechter A., Kemih K. and Ghanes M., "Backstepping control of a wind turbine for low wind speeds," Nonlinear Dynamics, vol. 84, pp. 2435-2445, 2016.

[19] Belmokhtar, K., Doumbia, M.L., Agbossou, K., "Modeling and control of a dual-power asynchronous machinebased wind turbine system for supplying power to the power grid (in French)," International Conference on Electrical Engeneering (CIGE), pp. 54-62, 2010.

[20] Hoang thinh do, Tri Dung Dang, Hoai Vu Anh Truong, Kyoung Kwan Ahn, "Maximum power point tracking and output power control on pressure coupling wind conversion system," IEEE Transactions on Industrial Electronics, vol. 65(2), 2018.

[21] Meng Wu, Le Xie, "Calculation steady-state operating conditions for DFIG-based wind turbine," IEEE Transactions on sustainable Energy, vol. 9(1), 2018. 
[22] Mohamed Nadour, Ahmed Essadki, Tamou Nasser, "Comparative analysis between PI \& Backstepping control strategies of DFIG driven by wind turbine," International journal of Renewable Energy Research, vol. 7(3), 2017.

[23] Mullane, A., Lightbody, G., "Yacamini, R.: Adaptive control of variable speed wind turbines," Rev. Energ. Ren. Power Eng, pp. 101-110, 2001.

[24] T.K Roy, M.A Mahmud; S.N. Islam, M. T. Oo Amanullah, "Direct Power Controller Design for Improving FRT Capabilities of DFIG-Based Wind Farms using a Nonlinear Backstepping Approach," 2018 8th International Conference on Power and Energy Systems (ICPES), 2018.

[25] T.K Roy, M.A Mahmud, A.M.T. Oo, "Nonlinear Backstepping Controller Design for Improving Fault Ride Through Capabilities of DFIG-Based Wind Farms," 2018 IEEE Power \& Energy Society General Meeting (PESGM), 2018

[26] M El Ghamrasni, H Mahmoudi and B Bossoufi, "Modelling and simulation of a wind system using variable wind regimes withBackstepping control of DFIG," 2018 IOP Conf. Ser.: Earth Environ. Sci. 161 012026, 2018.

[27] Adekanle O.S., Guisser M., Abdelmounim E., Aboulfatah M., "Observer-Based Adaptive Backstepping Control of Grid-Connected Wind Turbine Under Deep Grid Voltage Dip," In: El Hani S., Essaaidi M. (eds) Recent Advances in Electrical and Information Technologies for Sustainable Development. Advances in Science, Technology \& Innovation (IEREK Interdisciplinary Series for Sustainable Development), Springer, Cham, 2019. 